\title{
Protective Effect of Proton Pump Inhibitor for Survival in Patients with Gastroesophageal Reflux Disease and Idiopathic Pulmonary Fibrosis
}

\author{
Chang Min Lee, ${ }^{1}$ Dong Ho Lee, ${ }^{1,2 *}$ Byung Kyu Ahn, ${ }^{1}$ Jae Jin Hwang, ${ }^{1}$ Hyuk Yoon, ${ }^{1}$ Cheol Min Shin,${ }^{1,2}$ Young Soo Park, ${ }^{1,2}$ and \\ Nayoung Kim ${ }^{1,2}$ \\ ${ }^{I}$ Divison of Gastroenterology, Department of Internal Medicine, Seoul National University Bundang Hospital, Seongnam-si, Gyeonggi-do, Korea; \\ and ${ }^{2}$ Department of Internal Medicine, Seoul National University College of Medicine, Seoul, Korea
}

\section{Background/Aims}

The prevalence of gastroesophageal reflux disease (GERD) is high in patients with idiopathic pulmonary fibrosis (IPF). GERD may cause chronic microaspiration that leads to repeated subclinical lung injury, which leads to pulmonary fibrosis. Although some studies have suggested that proton pump inhibitors (PPI) were associated with a good prognosis in IPF, their effects remain unclear.

\section{Methods}

We retrospectively reviewed 786 consecutive adult patients with IPF at Seoul National University Bundang Hospital between April 2003 and March 2015.

\section{Results}

Mean duration of follow-up was $2.6 \pm 2.8$ years. Of the 786 patients with IPF, 107 (13.6\%) were given diagnoses of GERD, and 103 (13.1\%) died due to IPF-related pneumonia or respiratory failure. The prevalence of GERD and the cumulative incidence of de novo GERD increased depending on the period of follow-up in patients with IPF. Patients administered PPI for more than four months had a lower IPF-related mortality rate than patients on PPI less than 4 months (Log-rank $P$-value $=0.024$ in Kaplan-Meier curve). In a univariate and multivariate Cox regression hazard model, younger age (hazard ratio $[\mathrm{HR}], 1.06 ; 95 \% \mathrm{Cl}, 1.03-1.10 ; P=0.001$ ), higher initial forced vital capacity $(\mathrm{HR}, 0.98 ; 95 \% \mathrm{Cl}, 0.96-0.99 ; P=0.004)$, and longer duration of PPI use (HR, $0.97 ; 95 \% \mathrm{Cl}, 0.95-1.00 ; P$ $=0.022$ ), but not a diagnosis of GERD, were significantly associated with lower IPF-related mortality.

\section{Conclusions}

In Korean patients with IPF, the prevalence of GERD was lower than in other countries. PPI use for at least 4 months may have a protective effect against IPF-related mortality.

(J Neurogastroenterol Motil 2016;22:444-451)

\section{Key Words}

Gastroesophageal reflux; Idiopathic pulmonary fibrosis; Korea; Proton pump inhibitor; Risk factors

Received: December 5, 2015 Revised: January 18, 2016 Accepted: January 27, 2016

(a) This is an Open Access article distributed under the terms of the Creative Commons Attribution Non-Commercial License (http://creativecommons. org/licenses/by-nc/4.0) which permits unrestricted non-commercial use, distribution, and reproduction in any medium, provided the original work is properly cited.

${ }^{*}$ Correspondence: Dong Ho Lee, MD, PhD

Division of Gastroenterology, Seoul National University Bundang Hospital, 82 Gumi-ro 173 beon-gil, Bundang-gu, Seongnam, Gyeonggi-do 13620, Korea

Tel: +82-31-787-7006, Fax: +82-31-787-4051, E-mail: dhljohn@snubh.org 


\section{Introduction}

Previous studies have reported the relationship between gastroesophageal reflux disease (GERD) and respiratory disease, including asthma, chronic obstructive pulmonary disease (COPD), and idiopathic pulmonary fibrosis (IPF). ${ }^{1-3}$ In particular, many studies have reported the higher prevalence of GERD in IPF. ${ }^{4-13}$ The prevalence of GERD in patients with IPF was reportedly 67 to $88 \%$ in Western populations, ${ }^{8-10,12,13}$ and $62.3 \%$ (43 of 69 patients) in China. ${ }^{6}$ Although the mechanism is unclear, chronic microaspiration due to GERD has been considered to be one of the causes of IPF through repeated subclinical injury to the lungs. ${ }^{7,8,12,14-17}$ This is supported by the lower $\mathrm{pH}$ or elevated concentrations of pepsin in bronchoalveolar lavage in patients with IPF. ${ }^{18,19}$ Esophageal manometry in patients with GERD and IPF shows decreased lower esophageal sphincter pressure (LESP) with normal esophageal function, and further decreased upper esophageal sphincter pressure than LESP. ${ }^{6,20}$ These findings may explain why typical symptoms such as heartburn are uncommon in patients with IPF. ${ }^{6,14,16,20}$

Moreover, Lee et $\mathrm{al}^{21}$ reported that GERD influences the survival rate in patients with IPF, as well as the development of IPF. This study also reported that symptoms of GERD, a history of GERD, medication for GERD, and Nissen fundoplication were independent predictors of longer survival for IPF. Another study reported that antacid therapy including antihistamines, sucralfate, and proton pump inhibitors (PPI) reduced the frequency of acute exacerbations and slowed the deterioration of forced vital capacity (FVC). ${ }^{22}$ Another case series showed that anti-reflux therapy with PPI alone stabilized or improved pulmonary function tests in IPF. ${ }^{23}$

Standard treatment for atypical GERD has been proposed as PPI twice daily for 3-4 months. ${ }^{3,24}$ In cases of laryngopharyngeal reflux, some experts recommend treatment with PPI for at least 4-6 months in order to improve the symptoms. ${ }^{25,26}$ However, in respiratory manifestations of GERD, the appropriate duration and effectiveness of PPI medication are still controversial.

The aims of this study were to investigate the prevalence of GERD in Korean patients with IPF, and to compare the differences in survival according to the duration of PPI treatment.

\section{Materials and Methods}

\section{Study Populations}

This is a retrospective, single-center cohort study involving a total of 917 consecutive adult patients with IPF seen at Seoul National University Bundang Hospital between April 2003 and March 2015. Of these, patients with underlying asthma or COPD were excluded; therefore, a total of 786 patients were enrolled. All patients were given diagnoses of IPF by respiratory specialists. IPF is defined as a specific form of chronic, progressive, fibrosing interstitial pneumonia of unknown cause, occurring primarily and in association with histologic and/or radiologic patterns of usual interstitial pneumonia. ${ }^{27}$ Demographic data including age, sex, body mass index (BMI), concomitant diseases, alcohol consumption, smoking, medication history, pulmonary function, and computed tomography data were retrospectively collected from a review of medical records. GERD was diagnosed according to typical symptoms including typical heartburn and acid regurgitation. Erosive reflux disease (ERD) was defined by mucosal breaks on endoscopy, and nonerosive reflux disease (NERD) was diagnosed after reflux monitoring and/or PPI response in addition to negative endoscopy. This study was conducted in accordance with the amended Declaration of Helsinki. The Institutional Review Board of Seoul National University Bundang Hospital reviewed and approved the protocol (B-1507-306-126).

\section{Outcome}

The primary outcomes were the prevalence of GERD and cumulative incidence of de novo GERD in patients with IPF at Seoul National University Bundang Hospital in Korea. The secondary outcomes were IPF-related mortality and the predictive risk factors for IPF-related mortality according to variables, including duration of medication with PPI in patients with IPF.

\section{Statistical Methods}

For between-group comparisons, the Chi-square test or Fisher's exact test (for situations with small frequencies) was used for categorical variables, and Student's $t$ test was used for continuous variables. The cumulative incidence of de novo GERD and IPF-related mortality curves were constructed using Kaplan-Meier analysis, and compared using the log-rank test. The association between variables and IPF-related mortality was assessed by univariate and multivariate Cox proportional hazard regression analysis. The risk was expressed by calculating the hazard ratio (HR) and 95\% confidence interval (CI). A $P$-value $<0.05$ was considered to indicate a statistically significant difference. All statistical analyses were performed using SPSS 22.0 (SPSS, Chicago, IL, USA). 


\section{Results}

\section{Baseline Characteristics}

Mean age \pm standard deviation was $75.2 \pm 10.3$ years, and 559 (71.1\%) were men (Table 1). Mean BMI was $22.6 \pm 3.9$ $\mathrm{kg} / \mathrm{m}^{2}$. Mean duration of follow-up was $2.6 \pm 2.8$ years. A total 294 (37.4\%) were given prednisolone. Of the 128 who were given azathioprine, 118 (92.2\%) were coadministered prednisolone; azathioprine alone was given to 10 patients. Inhaled corticosteroids/ long-acting beta2-agonists (ICS/LABA) were used in $42(5.3 \%)$. We performed esophagogastroduodenoscopy (EGD) in $25.2 \%$ of cases, while esophageal manometry and 24-hour pH monitoring were done in only 2 patients.

There was no significant difference in mean age, BMI, and sex between patients with and without GERD. However, the proportion undergoing EGD was significantly higher for those with GERD than in those without GERD $(78.5 \%$ vs $16.8 \%, P<0.001)$ (Table 1). Initial FVC was significantly higher and duration of follow-up was also significantly longer in patients with GERD. In addition, hypertension (HTN), diabetes mellitus, and angina were more likely in patients with GERD.

\section{The Prevalence of Gastroesophageal Reflux Disease and the Cumulative Incidence of De Novo Gastroesophageal Reflux Disease in Idiopathic Pulmonary Fibrosis}

Of the 786 patients with IPF, GERD was diagnosed in 107 (13.6\%). Of these 107, $84(78.5 \%)$ underwent EGD for diagnosis of GERD, and 23 (21.5\%) with typical symptoms were given diagnoses without EGD (Table 1). Of 84 patients who underwent

Table 1. Baseline Characteristics of Patients with Idiopathic Pulmonary Fibrosis

\begin{tabular}{|c|c|c|c|c|}
\hline Variable & $\begin{array}{l}\text { Total patients } \\
(\mathrm{N}=786)\end{array}$ & $\begin{array}{l}\text { Patients with GERD } \\
\qquad(\mathrm{n}=107)\end{array}$ & $\begin{array}{l}\text { Patients without GERD } \\
\qquad(\mathrm{n}=679)\end{array}$ & $P$-value \\
\hline Age (yr) & $75.2 \pm 10.3$ & $75.2 \pm 9.9$ & $75.1 \pm 10.3$ & 0.945 \\
\hline Sex (male) & $559(71.1)$ & $78(72.9)$ & $481(70.8)$ & 0.662 \\
\hline $\operatorname{BMI}\left(\mathrm{kg} / \mathrm{m}^{2}\right)$ & $22.6 \pm 3.9$ & $22.5 \pm 3.8$ & $22.6 \pm 4.0$ & 0.849 \\
\hline Duration of follow-up (yr) & $2.6 \pm 2.8$ & $3.9 \pm 2.9$ & $2.3 \pm 2.8$ & $<0.001^{\mathrm{a}}$ \\
\hline Initial FVC (\% predicted) & $84.0 \pm 20.5$ & $89.3 \pm 19.8$ & $83.0 \pm 20.5$ & $0.006^{\mathrm{a}}$ \\
\hline Duration of PPI (wk) & $24.5 \pm 54.5$ & $47.9 \pm 88.9$ & $15.1 \pm 26.8$ & $0.001^{\mathrm{a}}$ \\
\hline Alcohol consumption & $195(37.2)$ & $29(36.3)$ & $166(37.4)$ & 0.846 \\
\hline Smoking history & $269(65.9)$ & $43(62.3)$ & $226(66.7)$ & 0.487 \\
\hline \multicolumn{5}{|l|}{ Medication history } \\
\hline Acetylcysteine & $385(49.0)$ & $67(62.6)$ & $318(46.8)$ & $0.002^{\mathrm{a}}$ \\
\hline Prednisolone & $294(37.4)$ & $40(37.4)$ & $254(37.4)$ & 0.996 \\
\hline Azathioprine & $128(16.3)$ & $16(15.0)$ & $112(16.5)$ & 0.688 \\
\hline Tiotropium & $46(5.9)$ & $8(7.5)$ & $38(5.6)$ & 0.441 \\
\hline ICS/LABA & $42(5.3)$ & $5(4.7)$ & $37(5.4)$ & 0.740 \\
\hline Warfarin & $26(3.3)$ & $4(3.7)$ & $22(3.2)$ & 0.771 \\
\hline Sildenafil & $19(2.4)$ & $7(6.5)$ & $12(1.8)$ & $0.009^{\mathrm{a}}$ \\
\hline EGD & $198(25.2)$ & $84(78.5)$ & $114(16.8)$ & $<0.001^{\mathrm{a}}$ \\
\hline Peptic ulcer disease & $55 / 198(27.8)$ & $26 / 84(31.0)$ & $29 / 114(25.4)$ & 0.392 \\
\hline \multicolumn{5}{|l|}{ Comorbidity } \\
\hline $\mathrm{HTN}$ & $143(18.2)$ & $32(29.9)$ & $111(16.3)$ & $0.001^{\mathrm{a}}$ \\
\hline $\mathrm{DM}$ & $125(15.9)$ & $22(20.6)$ & $103(15.2)$ & 0.156 \\
\hline Angina & $74(9.4)$ & $18(16.8)$ & $56(8.2)$ & $0.005^{\mathrm{a}}$ \\
\hline CKD & $11(1.4)$ & $0(0.0)$ & $11(1.6)$ & 0.377 \\
\hline $\mathrm{LC}$ & $6(0.8)$ & $0(0.0)$ & $6(0.9)$ & 1.000 \\
\hline Pulmonary HTN & $6(0.8)$ & $1(0.9)$ & $5(0.7)$ & 0.586 \\
\hline
\end{tabular}

${ }^{a} P$-value was below 0.05 .

GERD, gastroesophageal reflux disease; BMI, body mass index; FVC, forced vital capacity; PPI, proton pump inhibitor; ICS/LABA, inhaled corticosteroids/longacting beta2-agonists; EGD, esophagogastroduodenoscopy; HTN, hypertension; DM, diabetes mellitus; CKD, chronic kidney disease; LC, liver cirrhosis.

Data are presented as mean $\pm \mathrm{SD}$ or number (\%). 
EGD, the proportion with ERD was 18 (21.4\%), and 66 (78.6\%) had NERD (Fig. 1A). Of 679 IPF patients without GERD, 161 (23.7\%) used PPI for treatment of peptic ulcer or diagnosis of GERD.

On the other hand, 57/107 (53.3\%) were newly diagnosed with GERD following the diagnosis of IPF (de novo GERD) (Fig. 1B). However, the other cases of GERD (50/107, 46.7\%) were diagnosed before IPF was diagnosed.

The prevalence of GERD tended to increase as the followup period increased (Fig. 2A). In 736 patients without underlying GERD, the cumulative incidence of de novo GERD increased consistently after the diagnosis of IPF (Fig. 2B).

\section{Predictive Risk Factors for Idiopathic Pulmonary Fibrosis-related Mortality}

Of 786 patients with IPF, $156(19.8 \%)$ died regardless of the cause, and 103 (13.1\%) died due to IPF-related pneumonia or respiratory failure. In Kaplan-Meier analysis, IPF-related mortality was significantly lower in those who took PPI for more than four months than in those who took PPI for less than four months (log rank, $P=0.024)$. However, when the cut-off value was set at 2 or 3 months, there was no significant difference in IPF-related mortality (Fig. 3).

In the univariate Cox regression hazard model, IPF-related
A

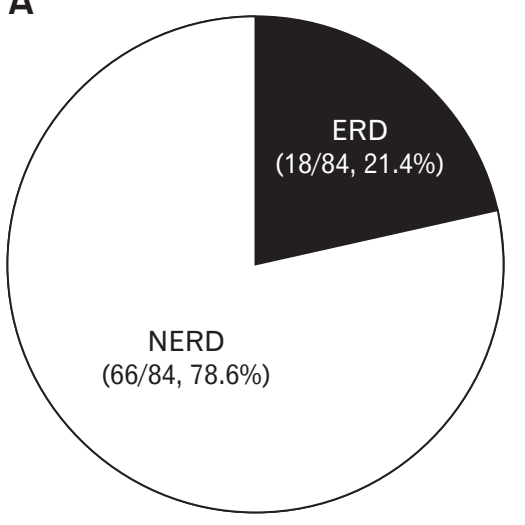

B

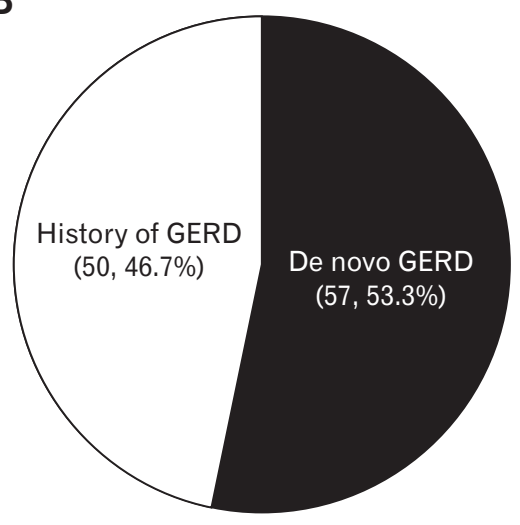

Figure 1. The distribution of gastroesophageal reflux disease (GERD) according to classification. (A) The proportion of erosive reflux disease (ERD) and non-erosive reflux disease (NERD) in GERD patients with esophagogastroduodenoscopy (EGD) $(\mathrm{n}=84)$. (B) The proportion of de novo GERD in patients with GERD $(\mathrm{n}=107)$.

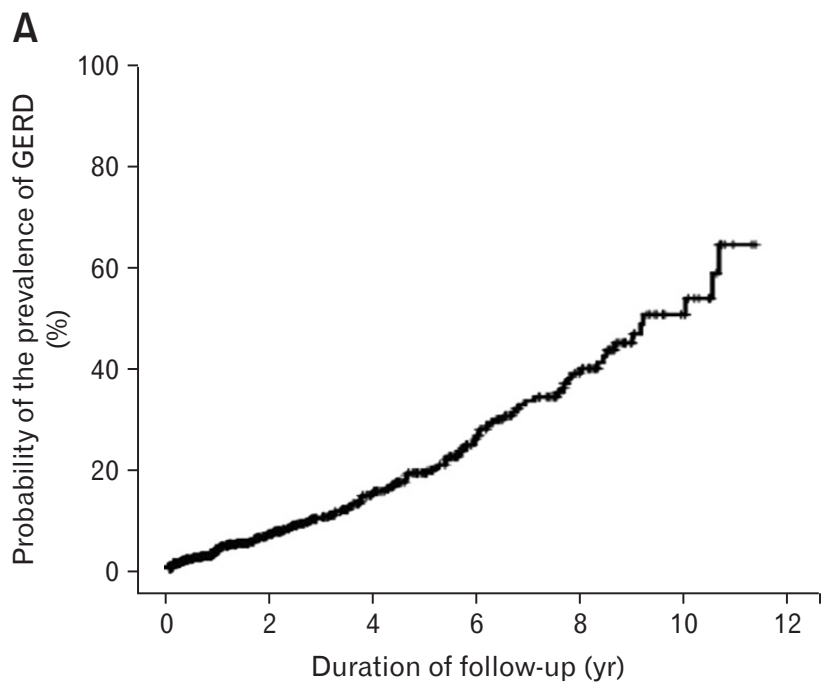

\begin{tabular}{|l|c|c|c|c|c|c|}
\hline Follow up period (years) & 0 & 2 & 4 & 6 & 8 & 10 \\
\hline Number of patient at risk (\%) & 100.0 & 92.0 & 84.6 & 72.9 & 56.9 & 46.5 \\
\hline
\end{tabular}

B

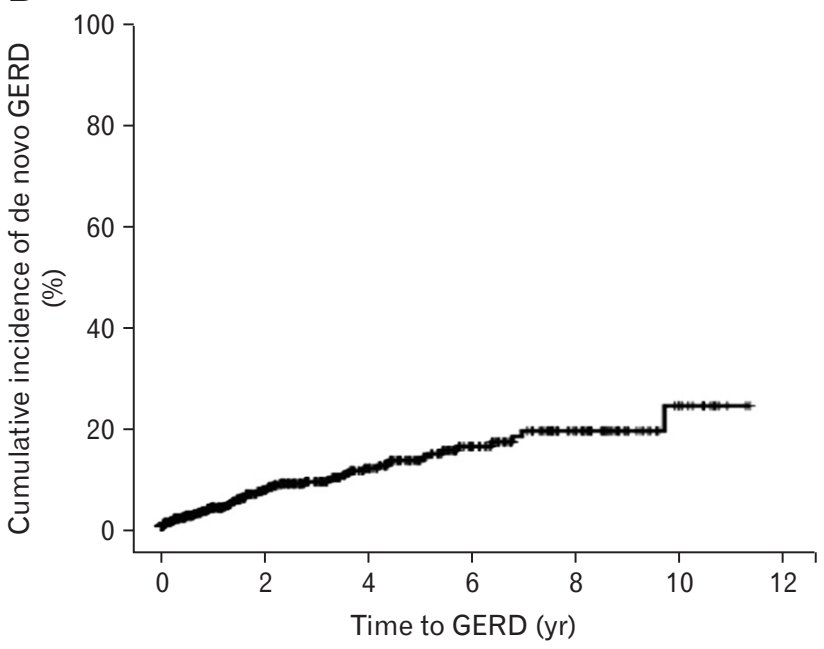

\begin{tabular}{|l|c|c|c|c|c|c|}
\hline Follow up period (years) & 0 & 2 & 4 & 6 & 8 & 10 \\
\hline Number of patient at risk (\%) & 100.0 & 92.1 & 86.3 & 80.6 & 77.7 & 73.4 \\
\hline
\end{tabular}

Figure 2. The prevalence and incidence of gastroesophageal reflux disease (GERD) in idiopathic pulmonary fibrosis (IPF). (A) Kaplan-Meier curves of the prevalence of GERD according to duration of follow-up in patients with IPF. (B) Kaplan-Meier curves of the cumulative incidence of de novo GERD after diagnosis of IPF. 
A
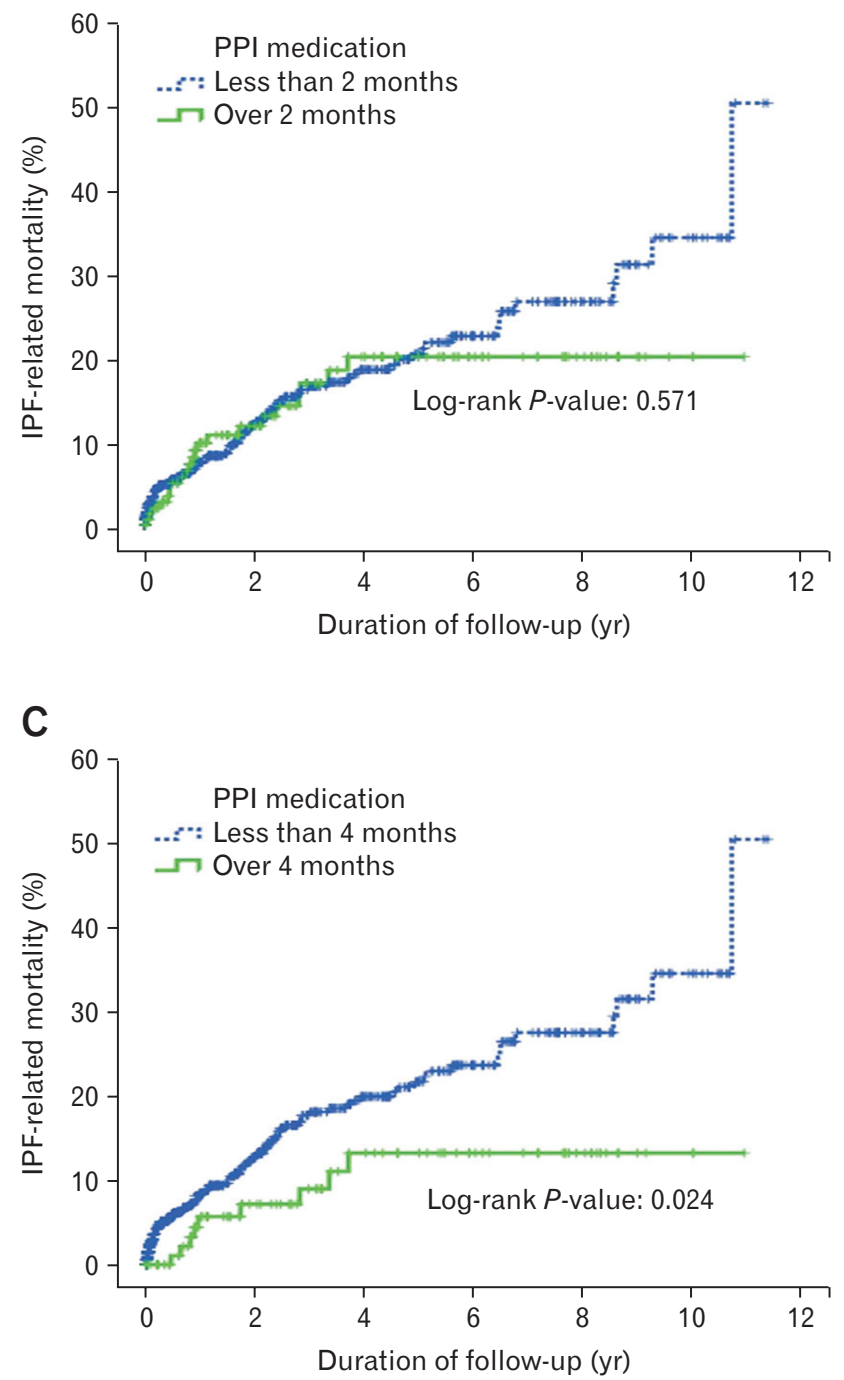

mortality was significantly associated with age, BMI, initial FVC, prednisolone, azathioprine, ICS/LABA, PPI for four months, duration of PPI use, underlying HTN, and pulmonary HTN (Table 2). In the multivariate Cox model 1, IPF-related mortality was significantly associated with age, initial FVC, azathioprine, pulmonary HTN, and duration of PPI use. However, in the multivariate Cox model 2, IPF-related mortality was associated with only age, initial FVC, and HTN, but not GERD or PPI dosing. In both multivariate Cox models, the hazard risk for IPF-related mortality increased with increasing age and decreasing initial FVC. However, there was no significant association between IPF-related mortality and GERD in either model. Although there was an inverse association between IPF-related mortality and duration of PPI dosing in model 1, PPI taken for 4 months was not a significant independent

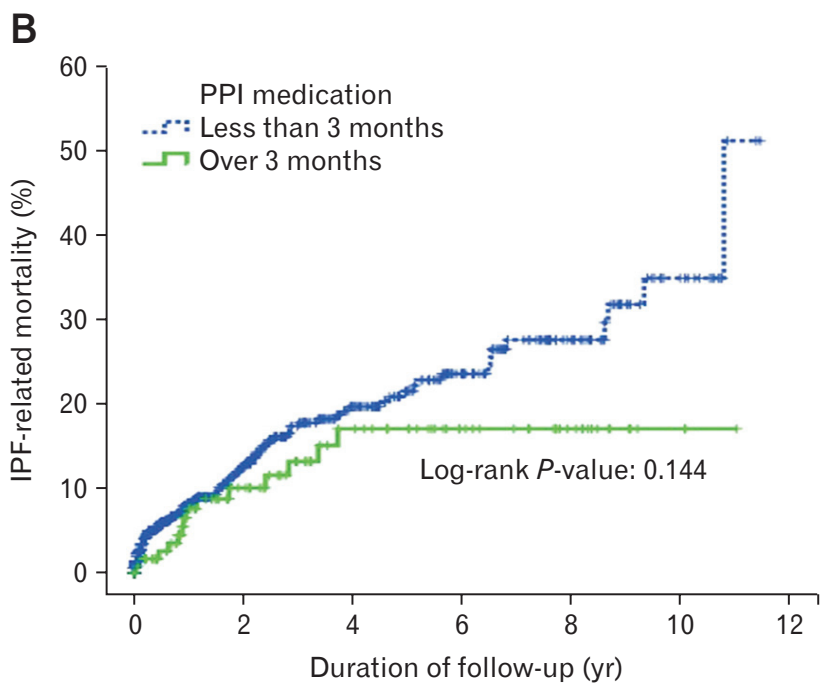

Figure 3. Kaplan-Meier estimates of idiopathic pulmonary fibrosis (IPF)-related mortality according to proton pump inhibitor (PPI) use. Green continuous line represents patients with PPI use over the cut-off value. Blue dotted line represents patients with PPI use for less than the cut-off value. (A) The cut-off value was 2 months, (B) 3 months, and (C) 4 months.

predictive factor for IPF-related mortality in model 2.

\section{Discussion}

In the present study, the prevalence of GERD was $13.6 \%$ (107/786) in patients with IPF in Korea. This result is much lower than the prevalence reported in other countries, including China. ${ }^{6,8-10,12,13}$ In addition, this result is lower than the prevalence of asthma or COPD previously reported in the Korean population (55.6\% and $30 \%$, respectively). ${ }^{28,29}$ While this low prevalence of GERD in IPF is probably due to ethnic characteristics in the Korean population, there is a possibility that GERD was diagnosed by gastroenterologists based on strict criteria. Furthermore, this may explain why typical GERD symptoms such as heartburn or reflux 
Table 2. Cox Regression Analysis of the Predictive Risk Factors for Idiopathic Pulmonary Fibrosis-related Mortality

\begin{tabular}{|c|c|c|c|c|c|c|}
\hline \multirow[t]{2}{*}{ Variable } & \multicolumn{2}{|c|}{ Univariate analysis } & \multicolumn{2}{|c|}{$\begin{array}{l}\text { Multivariate analysis } \\
\text { (Model 1) }\end{array}$} & \multicolumn{2}{|c|}{$\begin{array}{l}\text { Multivariate analysis } \\
\text { (Model 2) }\end{array}$} \\
\hline & $\operatorname{HR}(95 \% \mathrm{CI})$ & $P$-value & $\operatorname{HR}(95 \% \mathrm{CI})$ & $P$-value & $\operatorname{HR}(95 \% \mathrm{CI})$ & $P$-value \\
\hline Age (yr) & $1.03(1.01-1.05)$ & $0.005^{\mathrm{b}}$ & $1.06(1.03-1.10)$ & $0.001^{\mathrm{b}}$ & $1.05(1.02-1.09)$ & $<0.001^{\mathrm{b}}$ \\
\hline $\operatorname{BMI}\left(\mathrm{kg} / \mathrm{m}^{2}\right)$ & $0.92(0.88-0.97)$ & $0.003^{\mathrm{b}}$ & $1.01(0.92-1.11)$ & 0.872 & $0.99(0.92-1.06)$ & 0.729 \\
\hline Sex (male) & $0.78(0.49-1.22)$ & 0.270 & & & & \\
\hline Alcohol consumption & $1.24(0.83-1.85)$ & 0.305 & & & & \\
\hline Smoking history & $0.84(0.65-1.70)$ & 0.842 & & & & \\
\hline Initial FVC (\% predicted) & $0.98(0.97-0.98)$ & $<0.001^{\mathrm{b}}$ & $0.98(0.96-0.99)$ & $0.004^{\mathrm{b}}$ & $0.98(0.97-0.99)$ & $<0.001^{\mathrm{b}}$ \\
\hline Prednisolone & $2.09(1.41-3.11)$ & $<0.001^{\mathrm{b}}$ & $1.01(0.48-2.42)$ & 0.852 & $1.23(0.63-2.40)$ & 0.544 \\
\hline Azathioprine & $3.01(2.03-4.46)$ & $<0.001^{\mathrm{b}}$ & $2.79(1.31-5.94)$ & $0.008^{\mathrm{b}}$ & $1.85(0.99-3.46)$ & 0.056 \\
\hline ICS/LABA & $2.13(1.13-3.99)$ & $0.019^{\mathrm{b}}$ & $1.00(0.38-2.67)$ & 0.997 & $1.32(0.58-3.02)$ & 0.507 \\
\hline Tiotropium & $1.13(0.55-2.32)$ & 0.746 & & & & \\
\hline Acetylcysteine & $0.87(0.59-1.29)$ & 0.495 & & & & \\
\hline Sildenafil & $0.90(0.29-2.83)$ & 0.857 & & & & \\
\hline Warfarin & $0.44(0.11-1.77)$ & 0.246 & & & & \\
\hline PPI for 2 months $^{a}$ & $0.87(0.54-1.41)$ & 0.572 & & & & \\
\hline PPI for 4 months $^{a}$ & $0.47(0.23-0.92)$ & $0.028^{\mathrm{b}}$ & & & $0.51(0.21-1.22)$ & 0.130 \\
\hline Duration of PPI (wk) & $0.97(0.96-0.99)$ & $0.001^{\mathrm{b}}$ & $0.97(0.95-1.00)$ & $0.022^{\mathrm{b}}$ & & \\
\hline GERD & $0.40(0.20-0.80)$ & $0.009^{\mathrm{b}}$ & $0.62(0.26-1.46)$ & 0.274 & $0.72(0.33-1.58)$ & 0.413 \\
\hline NERD & $0.35(0.14-0.85)$ & $0.021^{\mathrm{b}}$ & & & & \\
\hline ERD & $0.05(0.00-6.73)$ & 0.228 & & & & \\
\hline Peptic ulcer & $1.09(0.43-2.73)$ & 0.857 & & & & \\
\hline Pulmonary HTN & $4.30(1.06-17.51)$ & $0.042^{\mathrm{b}}$ & $37.89(4.10-349.89)$ & $0.001^{\mathrm{b}}$ & $5.45(0.71-41.97)$ & 0.104 \\
\hline HTN & $0.52(0.30-0.90)$ & $0.020^{\mathrm{b}}$ & $0.55(0.25-1.20)$ & 0.134 & $0.50(0.26-0.99)$ & $0.046^{\mathrm{b}}$ \\
\hline $\mathrm{DM}$ & $1.11(0.69-1.78)$ & 0.663 & & & & \\
\hline Angina & $0.60(0.28-1.30)$ & 0.194 & & & & \\
\hline CKD & $0.05(0.00-17.88)$ & 0.313 & & & & \\
\hline
\end{tabular}

${ }^{a}$ Categorical variables were used in the analysis.

${ }^{\mathrm{b}} \mathrm{P}$-value was below 0.05 .

$\mathrm{HR}$, hazard ratio; BMI, body mass index; FVC, forced vital capacity; ICS/LABA, inhaled corticosteroids/long-acting beta2-agonists; PPI, proton pump inhibitor; GERD, gastroesophageal reflux disease; NERD, non-erosive reflux disease; ERD, erosive reflux disease; HTN, hypertension; DM, diabetes mellitus; CKD, chronic kidney disease.

were uncommon in patients with respiratory manifestations of GERD. ${ }^{6,14,16,20}$ Another possibility is that the prevalence of GERD may have been underestimated in the present study, because $31.8 \%$ (248/786) were lost to follow-up within six months. Among patients who continued follow-up for over six months, the prevalence of GERD in IPF was slightly increased to $17.3 \%$ (93/538). Furthermore, a longer duration of follow-up tended to increase the prevalence of GERD (up to $65.3 \%$ on the Kaplan-Meier curve) (Fig. 1A).

We investigated the time to onset of GERD, and found that of 107 patients with GERD and IPF, 50 (46.7\%) had been diagnosed with GERD before a diagnosis of IPF, and 57 (53.3\%) were newly diagnosed after a diagnosis of IPF. This suggests that GERD could occur at any time, regardless of the diagnosis of IPF. In 736 patients without underlying GERD at the time of diagnosis of IPF, the cumulative incidence of de novo GERD showed a tendency to continuous increase (Fig. 2B). However, there was no predictive factor for the development of de novo GERD in patients with IPF.

IPF-related causes of death, including pneumonia or respiratory failure, totaled $13.1 \%$ (103/786), and death due to any cause totaled $19.8 \%$ (156/786). In the present study, older age and lower initial FVC increased IPF-related mortality significantly in multivariate Cox regression analysis (Table 2). Although a history of azathioprine use was also associated with more frequent IPF-related deaths, this association may be due to confounding factors based on the severity of IPF. In a retrospective cohort study in the USA, Lee et $\mathrm{al}^{21}$ reported that the presence of reflux symptoms, GERD, GERD medication, and Nissen fundoplication were significantly 
associated with longer survival time. Similar to these results, GERD was also significantly associated with lower IPF-related death in univariate Cox analysis in the present study. However, in multivariate Cox regression analysis, GERD itself was not an independent predictive factor for IPF-related mortality (Table 2). On the contrary, PPI use was correlated with IPF mortality in the present study.

Compared to previous studies, PPI use for longer periods was associated with a reduced IPF-related mortality rate. Although PPI use for two or three months was not significantly correlated, PPI use for over four months showed a lower IPF-related mortality rate than use for less than four months (Fig. 2). In addition, longer duration of PPI use was a significant independent predictive factor for low IPF-related mortality rates in univariate and multivariate Cox regression analysis (Table 2). These results suggest that PPI use is associated with good prognosis in IPF, and that use of PPI for at least four months may have a protective effect against IPFrelated death. However, longer PPI use had a higher correlation with IPF-related mortality than did GERD. Because patients with GERD had a higher proportion of PPI use than patients without GERD $(P<0.001)$, the association between GERD and survival in univariate analysis was probably due to an association between GERD and PPI use. Patients with GERD had another basis for good prognosis. We surmised that IPF-related mortality may be influenced by better FVC at baseline in patients with GERD than in those without GERD (Table 1).

The main limitation of the present study was that it was a single-center retrospective study. In addition, the lower prevalence and mortality rates compared to those in previous studies may have been due to the higher proportion of loss to follow-up within 6 months. Insufficient evaluation of patients without GERD symptoms may also have contributed to underestimation. Furthermore, it should be noted that it was difficult to analyze atypical symptoms of GERD due to uncertainty of relationship between GERD and these symptoms. Therefore, further prospective studies are needed to verify the effectiveness of PPI in improving the prognosis of IPF. Another limitation is that PPI is also related with community-acquired pneumonia (CAP), and CAP is associated with IPF-related mortality. Although CAP might be a confounding factor, this is a rare data that improve a statistically significant relationship between PPI and IPF-related mortality. Moreover, there are no data available regarding patients with IPF and GERD in Korea.

In conclusion, in Korean patients with IPF, the prevalence of GERD was relatively low, compared to other countries. PPI treatment was more important to survival than GERD itself in patients with IPF. The IPF-related mortality rate was significantly associated with the use of PPI medication for longer than four months in patients with IPF.

Acknowledgements: The authors are indebted to J. Patrick Barron, Professor Emeritus, Tokyo Medical University and Adjunct Professor, Seoul National University Bundang Hospital for his pro bono editing of this manuscript.

\section{Financial support: None.}

\section{Conflicts of interest: None.}

Author contributions: Chang Min Lee and Dong Ho Lee had full access to all of the data in the study and take responsibility for the integrity of the data and the accuracy of the data analysis; Dong Ho Lee had final responsibility for the decision to submit the manuscript for publication; Hyuk Yoon, Cheol Min Shin, Young Soo Park, and Nayoung Kim contributed to the study concept and study design, data acquisition, and data analysis; Byung Kyu Ahn and Jae Jin Hwang contributed to the data acquisition and data analysis; and Cheol Min Shin and Dong Ho Lee contributed to the study design, data acquisition, data analysis and interpretation, and writing of the manuscript.

\section{References}

1. el-Serag HB, Sonnenberg A. Comorbid occurrence of laryngeal or pulmonary disease with esophagitis in United States military veterans. Gastroenterology 1997;113:755-760.

2. Galmiche JP, Zerbib F, Bruley des Varannes S. Review article: respiratory manifestations of gastro-oesophageal reflux disease. Aliment Pharmacol Ther 2008;27:449-464.

3. Richter JE. Review article: extraoesophageal manifestations of gastrooesophageal reflux disease. Aliment Pharmacol Ther 2005;22(suppl 1):70-80.

4. Bandeira CD, Rubin AS, Cardoso PF, Moreira Jda S, Machado Mda M. Prevalence of gastroesophageal reflux disease in patients with idiopathic pulmonary fibrosis. J Bras Pneumol 2009;35:1182-1189.

5. Basseri B, Conklin JL, Pimentel M, et al. Esophageal motor dysfunction and gastroesophageal reflux are prevalent in lung transplant candidates. Ann Thorac Surg 2010;90:1630-1636.

6. Gao F, Hobson AR, Shang ZM, et al. The prevalence of gastro-esophageal reflux disease and esophageal dysmotility in Chinese patients with idiopathic pulmonary fibrosis. BMC Gastroenterol 2015;15:26.

7. Mays EE, Dubois JJ, Hamilton GB. Pulmonary fibrosis associated with tracheobronchial aspiration. A study of the frequency of hiatal hernia and gastroesophageal reflux in interstitial pulmonary fibrosis of obscure etiol- 
ogy. Chest 1976;69:512-515

8. Patti MG, Tedesco P, Golden J, et al. Idiopathic pulmonary fibrosis: how often is it really idiopathic? J Gastrointest Surg 2005;9:1053-1056; discussion 1056-1058.

9. Raghu G, Freudenberger TD, Yang S, et al. High prevalence of abnormal acid gastro-oesophageal reflux in idiopathic pulmonary fibrosis. Eur Respir J 2006;27:136-142.

10. Salvioli B, Belmonte G, Stanghellini V, et al. Gastro-oesophageal reflux and interstitial lung disease. Dig Liver Dis 2006;38:879-884.

11. Soares RV, Forsythe A, Hogarth K, Sweiss NJ, Noth I, Patti MG. Interstitial lung disease and gastroesophageal reflux disease: key role of esophageal function tests in the diagnosis and treatment. Arq Gastroenterol 2011;48:91-97.

12. Sweet MP, Patti MG, Leard LE, et al. Gastroesophageal reflux in patients with idiopathic pulmonary fibrosis referred for lung transplantation. J Thorac Cardiovasc Surg 2007;133:1078-1084.

13. Tobin RW, Pope CE 2nd, Pellegrini CA, Emond MJ, Sillery J, Raghu G. Increased prevalence of gastroesophageal reflux in patients with idiopathic pulmonary fibrosis. Am J Respir Crit Care Med 1998;158:1804-1808.

14. Lee JS. The role of gastroesophageal reflux and microaspiration in idiopathic pulmonary fibrosis. Clin Pulm Med 2014;21:81-85.

15. Lee JS, Collard HR, Raghu G, et al. Does chronic microaspiration cause idiopathic pulmonary fibrosis? Am J Med 2010;123:304-311.

16. Raghu G, Meyer KC. Silent gastro-oesophageal reflux and microaspiration in IPF: mounting evidence for anti-reflux therapy? Eur Respir J 2012;39:242-245.

17. Verma S, Slutsky AS. Idiopathic pulmonary fibrosis--new insights. N Engl J Med 2007;356:1370-1372.

18. Davis CS, Mendez BM, Flint DV, et al. Pepsin concentrations are elevated in the bronchoalveolar lavage fluid of patients with idiopathic pulmonary fibrosis after lung transplantation. J Surg Res 2013;185:e101e108.

19. Lozo Vukovac E, Lozo M, Mise K, et al. Bronchoalveolar $\mathrm{pH}$ and inflammatory biomarkers in newly diagnosed IPF and GERD patients: a case-control study. Med Sci Monit 2014;20:255-261.

20. Allaix ME, Fisichella PM, Noth I, Herbella FA, Borraez Segura B, Patti MG. Idiopathic pulmonary fibrosis and gastroesophageal reflux. Implications for treatment. J Gastrointest Surg 2014;18:100-104; discussion 104-105.

21. Lee JS, Ryu JH, Elicker BM, et al. Gastroesophageal reflux therapy is associated with longer survival in patients with idiopathic pulmonary fibrosis. Am J Respir Crit Care Med 2011;184:1390-1394.

22. Lee JS, Collard HR, Anstrom KJ, et al. Anti-acid treatment and disease progression in idiopathic pulmonary fibrosis: an analysis of data from three randomised controlled trials. Lancet Respir Med 2013;1:369-376.

23. Raghu G, Yang ST, Spada C, Hayes J, Pellegrini CA. Sole treatment of acid gastroesophageal reflux in idiopathic pulmonary fibrosis: a case series. Chest 2006;129:794-800.

24. Heidelbaugh JJ, Gill AS, Van Harrison R, Nostrant TT. Atypical presentations of gastroesophageal reflux disease. Am Fam Physician 2008;78:483-488.

25. Belafsky PC, Postma GN, Koufman JA. Laryngopharyngeal reflux symptoms improve before changes in physical findings. Laryngoscope 2001;111:979-981.

26. Vaezi MF, Hicks DM, Abelson TI, Richter JE. Laryngeal signs and symptoms and gastroesophageal reflux disease (GERD): a critical assessment of cause and effect association. Clin Gastroenterol Hepatol 2003;1: 333-344.

27. Raghu G, Collard HR, Egan JJ, et al. An official ATS/ERS/JRS/ALAT statement: idiopathic pulmonary fibrosis: evidence-based guidelines for diagnosis and management. Am J Respir Crit Care Med 2011;183:788824.

28. Kim SW, Lee JH, Sim YS, Ryu YJ, Chang JH. Prevalence and risk factors for reflux esophagitis in patients with chronic obstructive pulmonary disease. Korean J Intern Med 2014;29:466-473.

29. Lee YB, Lim JH, Choi YJ, et al. [Effects of proton pump inhibitors in asthmatics with gastroesophageal reflux disease.] Korean J Gastroenterol 2011;58:178-183. [Korean] 